\title{
HE4 is a novel tissue marker for therapy response and progestin resistance in medium- and low-risk endometrial hyperplasia
}

\author{
Anne Ørbo*,1,2, Marit Arnes², Lena Myreng Lyså ${ }^{2}$, Christer Borgfelt ${ }^{3}$ and Bjørn Straume ${ }^{4}$ \\ ${ }^{1}$ Department of Clinical Pathology, University Hospital of Tromsø, N-9038 Tromsø, Norway; ${ }^{2}$ Research Group for Gynaecologic \\ Oncology, Department of Medical Biology, Faculty of Health Sciences, University of Tromsø, N-9037 Tromsø, Norway; \\ ${ }^{3}$ Department of Obstetrics and Gynecology, Skåne University Hospital, Lund, Sweden and ${ }^{4}$ Department of Community Medicine, \\ Faculty of Health Sciences, University of Tromsø, N-9037 Tromsø, Norway
}

Background: The aim of the present study was to investigate whether changes in the tissue expression of human epididymisspecific protein 4 (HE4) could predict therapy resistance and relapse after progestin hormone therapy for medium- and low-risk endometrial hyperplasia.

Methods: Endometrial biopsies were obtained from women participating in a multicentre RCT performed according to the CONSORT guidelines; the women were randomly assigned to either LNG-IUS; $10 \mathrm{mg}$ of oral medroxyprogesterone acetate (MPA) administered for 10 days per cycle; or $10 \mathrm{mg}$ of oral MPA administered daily for 6 months. Of the 153 women who completed therapy, 141 had adequate material for immunohistochemistry in pre- and post-treatment biopsies. An antibody to HE4 (clone 12A2 monoclonal lgG1 antibody, Fujirebio Diagnostics, Inc.) was used for the immunohistochemical staining of the pre- and post-treatment biopsies from each participant. The expression of HE4 staining was evaluated by the histological score (H-score) using light microscopy.

Results: Changes in the expression of HE4 ( $H$-score) during therapy were related to the therapy group $(P<0.001)$ and therapy response $(P<0.001)$ of the individuals but could not predict relapse $(P>0.05)$. Changes in the intracellular bodies were shown to predict both the therapy response $(P=0.038)$ and relapse $(P=0.014)$.

Conclusions: Changes in the expression of HE4 during progestin therapy regimens can predict therapy response or indicate progestin resistance for medium- and low-risk endometrial hyperplasia.

Endometrial cancer, presently the most common gynaecological malignancy in the western world, is still increasing in prevalence (Okuda et al, 2010; Rodriguez et al, 2016). As much as $80 \%$ of endometrial cancers are preceded by a preliminary stage called endometrial hyperplasia. Therefore, the development of optimal diagnostics and individualised therapy for endometrial hyperplastic lesions should be of high priority to prevent this trend. However, national routines for therapy and follow up for endometrial hyperplasia have thus far been arbitrary or non- existing (Kurman et al, 1985; Gallos et al, 2013b). In recent decades, progestin has been accepted as a conservative therapy for low- and medium-risk endometrial hyperplasia (Ferenczy and Gelfand, 1989; Jobo et al, 2001; Bese et al, 2006; Clark et al, 2006; Orbo et al, 2008). A levonorgestrel-impregnated intrauterine device (LNG-IUS, Mirena, Bayer, Berlin, Germany) has recently been demonstrated to be superior to oral progestin (Wildemeersch et al, 2007; Varma et al, 2008; Buttini et al, 2009; Gallos et al, 2010; Orbo et al, 2014; Abu et al, 2015), but oral regimens are still

*Correspondence: Professor A Ørbo; E-mail: anne.orbo@uit.no 
preferred by many women with intolerance to intrauterine therapy. However, most of the published data indicate a high frequency of progestin resistance or therapy failure after oral regimes compared with intrauterine treatment (Gallos et al, 2013a). In a recent RCT, we found that $31 \%$ of individuals failed to respond after cyclic oral therapy lasting for 6 months (Orbo et al, 2014). However, to date, no objective molecular marker for resistance to progestin therapy has been identified.

Human epididymis-specific protein 4 ( $\mathrm{HE} 4$, belonging to one of four WAP gene products), has been shown to be secreted into the serum as a glycoprotein overexpressed in serous and endometrioid types of ovarian carcinomas (Drapkin et al, 2005; Bouchard et al, 2006). The exact function of the HE4 protein is unknown, but previous studies have demonstrated that HE4 overexpression promotes cell adhesion and migration whereas HE4 suppression markedly inhibits tumour growth (Lu et al, 2012).

In the past decade, HE4 has drawn attention as a serum marker for endometrial cancer (Moore et al, 2011; Kalapotharakos et al, 2012). Thus, HE4 has been shown to be a promising marker for the detection and prognosis of endometrial cancer with respect to the Figo stage, myometrial invasion, and grade (Moore et al, 2008; Bignotti et al, 2011; Moore et al, 2011; Mutz-Dehbalaie et al, 2012). Immunohistochemical detection of HE4 in endometrial tissue samples revealed that the rate of expression of HE4 in endometrial hyperplasia was higher compared with normal controls and lower compared with individuals with endometrial cancer (Deng et al, 2015; Li et al, 2015). However, hormone-mediated regulation of HE4 tissue expression by progestin has never been described, and no studies exist of HE4 as a predictive marker of the therapy response after progestin therapy for endometrial hyperplasia.

The present study was based on a national multicentre RCT comparing different progestin regimens as a treatment for endometrial hyperplasia (Orbo et al, 2014; Orbo et al, 2015). Our main intention was to investigate whether variation in the tissue expression of HE4 during different progestin therapy regimens could predict therapy response or therapy failure and whether HE4 might be considered a potential marker for progestin resistance for medium- and low-risk endometrial hyperplasia.

\section{MATERIALS AND METHODS}

Patients. The biopsy material was obtained from 153 women with low- and medium-risk endometrial hyperplasia in a national multicentre randomised study (Orbo et al, 2014). The women had been treated with either LNG-IUS (Mirena, Bayer), $10 \mathrm{mg}$ of medroxyprogesterone acetate (MPA) for 10 days per cycle, or $10 \mathrm{mg}$ of MPA daily for 6 months (ClinicalTrials.gov, NCT01074892, Regional Ethical committee number 25/2004) (Orbo et al, 2014). The study inclusion period was from 1 January 2005 to 1 November 2011. The treatment period was completed on 1 May 2012. After 6 months of treatment, all therapy was withdrawn. One pre- and one post-treatment biopsy (after 6 months) was obtained from each participant using a Pipelle (Endometrial suction curette, Jiangsu Guard King Medical Equipment, Jiangsu, China) (Orbo et al, 2014). For the present study, paired adequate biopsy material from 141 women was available for the immunohistochemical analyses; 48 of these women had been treated with LNG-IUS; 44 with continuous MPA; and 49 with cyclic MPA. Insufficient biopsy material in the paraffin blocks was the reason for excluding eight of the original 153 women. Patient characteristics, such as age, menopausal status, parity, and WHO diagnosis, were registered and related to the staining of HE4 in tissue specimens taken before the start of therapy and when therapy was discontinued (after 6 months). To monitor relapse, all the included patients were followed up at 6month intervals for 24 months after therapy was discontinued.

Endometrial biopsies. The endometrial biopsy material was sent to the Department of Pathology at the University Hospital of North Norway for routine assessment. The specimens were fixed in buffered formaldehyde, embedded in paraffin, and further processed in the laboratory before standard histological sections were obtained. Diagnostic assessment of the WHO classification by light microscopy was performed by a trained gynaecology pathologist $(\mathrm{AO})$ and one additional routine pathologist; each was blinded to the other's diagnosis. Agreement after discordant results was always obtained after discussion at a two-headed microscope. The index biopsies were classified into one of the three groups: simple hyperplasia, complex hyperplasia, or atypical hyperplasia, according to the WHO classification, which was considered the gold standard for the evaluation of endometrial hyperplasia at the time the study was performed (Kurman et al, 1985; Gallos et al, 2013b). Normalised histology in the control biopsies after therapy was defined as ordinary proliferative endometrium or endometrium with a progestin effect (Kurman et al, 1985; Gallos et al, 2013b). All information from the WHO classification of the index and control biopsies was registered and maintained in a separate database and subsequently supplemented with information from hospital records.

Immunohistochemistry. Immunohistochemistry was performed according to customers' advice. Slides with a thickness of 4-5 $\mu \mathrm{m}$ were routinely cut from paraffin blocks and placed on Super frost + glasses (Fisher Scientific, Oslo, Norway), followed by incubation overnight at $60^{\circ} \mathrm{C}$, which was necessary for fixation. Deparaffinisation, pretreatment in a Tris-based, slightly alkaline reagent (CC1 mild) for $30 \mathrm{~min}$ at $95^{\circ} \mathrm{C}$ and staining were automatically performed in a Benchmark XT from Ventana Medical Systems, Inc (Tucson, AZ, USA). The primary antibody used in the present study was HE4 clone 12A2 monoclonal IgG1 antibody (Fujirebio Diagnostics, Inc., PA, USA). The initial concentration was $15.1 \mathrm{mg} \mathrm{ml}^{-1}$, and the antibody was used at a dilution of lout of 4000 in Antibody Diluent (Ventana Medical Systems, Inc.). After addition of the primary antibody, the slides were incubated for $32 \mathrm{~min}$ at $37^{\circ} \mathrm{C}$, and automatic DAB staining was performed in several steps with an Ultraview Universal DAB Detection kit (Ventana Medical Systems, Inc.) before dehydration, counterstaining with haematoxylin, and mounting.

Evaluation of immunohistochemical expression in endometrial glands (H-score). The results of immunostaining in endometrial hyperplasia specimens taken before therapy and immediately after 6 months of progestin therapy were assessed by light microscopy. The HE4 staining, which was concentrated mainly within the cytoplasm of endometrial glandular cells, was examined using a semi-quantitative immunohistochemical histological score ( $H$-score), which incorporates both the intensity and the distribution of specific staining (Huang et al, 1996). The immunohistochemical staining results were classified as follows: light-brown granular cytoplasm $=1$, medium-brown granular cytoplasm $=2$, or dark-brown granular cytoplasm $=3$. The $H$-score has been previously formulated as $\mathrm{HS}=\sum(\mathrm{Pi} \times i) / 100$, in which $\mathrm{Pi}$ denotes the percentage of stained cells and $i$ denotes the intensity of the staining, ranging from 1-3 (Huang et al, 1996). The $H$-score evaluation was performed visually as a consensus between a trained gynaecological pathologist (AO) and a trained technician (MA). Both investigators were blinded to the different patient groups, and three specific areas within each specimen (hot spots) were defined for investigation in the pre- and post-therapy biopsy specimens. The staining intensity and the number of positive cells were evaluated. The $H$-scores for the cells in the pre-treatment biopsies were used to divide the samples into three groups: low 
( $H$-score $>0.5)$, medium ( $H$-score $0.6-1.5)$, and high ( $H$-score $>1.6)$. A statistical evaluation of the differences in the $H$-scores between the pre- and post-treatment biopsies related to therapy group, therapy response, and relapse was used to divide the patients as follows: patients with reduced $H$-scores after therapy were placed in group 1 , and patients with unchanging or increased $H$-scores were placed in group 2. Aggregates of dark-brown, welldefined material (bodies) were observed within the cytoplasm of the endometrial glands. These bodies showed variations in size and were classified as follows: absence of bodies $-0 ;<2-4 \mu \mathrm{m}$ in diameter -1 ; 5-10 $\mu \mathrm{m}$ in diameter-2; and 11-15 $\mu \mathrm{m}$ diameter-3. Changes in the diameter of the bodies between pre- and posttreatment specimens were divided into two separate groups and evaluated according to the therapy group, therapy response, and relapse.

Ethical approval. The study following the Helsinki declaration was designed according to the CONSORT statement for randomised clinical trials (Schulz et al, 2010), was approved by the Regional Committee for Medical and Health Research Ethics (number 25/2004), by the Norwegian Council of Medical Advice, and by the Norwegian Medicines Agency. The study was registered in the ClinicalTrials.gov NCT01074892.

Statistics. All statistical analyses were performed in simple cross tables, and $P$-values for the $\chi^{2}$ - tests are reported.

\section{RESULTS}

Patients. Among the 153 women originally included in this study, all of those treated with LNG-IUS had a complete response (normal proliferative endometrium or endometrium with atrophic glands and pseudo-decidualised stroma) after 6 months of treatment. Only 69\% of those treated with cyclic oral progestin (10 mg of MPA, 10 days per cycle) had a response, and of the women treated daily with oral MPA (10 mg), 96\% had a response after 6 months (Orbo et al, 2014). In the present study, biopsies from 141 of the 153 women were available for the immunohistochemical analyses. Among these women, 123 were responders and 18 were non-responders. All of the 48 women treated with the LNG-IUS were responders. In addition, 33 of the 49 women treated with cyclic MPA and 42 of the 44 women treated with continuous MPA were responders. The mean ages of the responding and non-responding women were 47.6 and 48.4 years, respectively.

During the 24 months of follow up, 50 women were diagnosed with relapse, of which 10 were in the cyclic oral group, 19 were in the continuous oral group, and 21 were in the LNG-IUS group (Orbo et al, 2015).

$\boldsymbol{H}$-score before therapy. All of the endometrial biopsy specimens from the 141 women with endometrial hyperplasia showed the expression of HE4 in the glands before the start of therapy, but the majority of cases expressed moderate staining. In the LNG-IUStreated group $(n=48), 3(6 \%)$ had low $H$-scores $(<0.5), 33(69 \%)$ had medium $H$-scores $(0.6-1.0)$, and $12(25 \%)$ had high $H$-scores $(>1)$ before therapy. In the group treated with continuous oral progestin $(n=44)$, none had low $H$-scores, 37 (84\%) had medium $H$-scores, and $7(16 \%)$ had high $H$-scores before the start of therapy. In the group treated with cyclic oral progestin $(n=49)$, $5(10 \%)$ had low $H$-scores, $39(80 \%)$ had medium $H$-scores, and 5 (10\%) had high $H$-scores.

Changes in $\boldsymbol{H}$-scores related to progestin therapy regimen. The changes in the $H$-scores in the endometrial glands for the three therapy groups were significantly related to the therapy regimen $(P<0.001)$; details are shown in Table 1 . Human epididymisspecific protein 4 expression before therapy in the glands is reported in Figure 1A. The changes in the $H$-scores of the
Table 1. Change in the $H$-score (difference in pre- and posttreatment biopsies) in the three therapy groups $(10 \mathrm{mg}$ of MPA for 10 days per cycle, $10 \mathrm{mg}$ of MPA daily, or the levonorgestrel impregnated intrauterine system for 6 months) in a randomised controlled trial in women with endometrial hyperplasia $(n=141)$ related to the therapy regimen used

\begin{tabular}{|l|c|c|c|}
\hline $\begin{array}{l}\text { Therapy/HE4 } \\
\text { expression }\end{array}$ & $\begin{array}{c}\text { Reduced or } \\
\text { absent HE4 } \\
\text { expression after } \\
\text { therapy } \\
\mathbf{N}\end{array}$ & $\begin{array}{c}\text { Increased or } \\
\text { persistent HE4 } \\
\text { expression after } \\
\text { therapy } \\
\mathbf{N}\end{array}$ & Total \\
\hline Oral cyclic progestin & 13 & 36 & 49 \\
\hline Oral continuous & $26.5 \%$ & $73.5 \%$ & 100.0 \\
progestin & 20 & 24 & 44 \\
\hline LNG-IUS & $45.4 \%$ & $54.6 \%$ & 100.0 \\
\hline Total & 33 & 15 & 48 \\
& $68.7 \%$ & $31.3 \%$ & 100.0 \\
\hline Antor & 66 & 75 & 141 \\
\hline
\end{tabular}

Abbreviations: $\mathrm{HE} 4=$ human epididymis-specific protein $4 ; \mathrm{H}$-score=histological score; MPA $=$ medroxyprogesterone acetate. $\chi^{2}: P<0.001$.

Table 2. Change in the H-score (difference in pre- and posttreatment biopsies) in patients with and without therapy response $(n=141)$ after 6 months of progestin therapy $(10 \mathrm{mg}$ of MPA for 10 days per cycle, $10 \mathrm{mg}$ of MPA daily, or the levonorgestrel impregnated intrauterine system for 6 months) in a randomised controlled trial in women with endometrial hyperplasia

\begin{tabular}{|c|c|c|c|}
\hline $\begin{array}{l}\text { Response/HE4 } \\
\text { expression }\end{array}$ & $\begin{array}{c}\text { Reduced or } \\
\text { absent HE4 } \\
\text { expression after } \\
\text { therapy } \\
\mathbf{N}\end{array}$ & $\begin{array}{c}\text { Increased or } \\
\text { persistent HE4 } \\
\text { expression after } \\
\text { therapy } \\
\mathbf{N}\end{array}$ & Total \\
\hline $\begin{array}{l}\text { Not responding to } \\
\text { therapy }\end{array}$ & $\begin{array}{c}1 \\
5.6 \%\end{array}$ & $\begin{array}{c}17 \\
94.4 \%\end{array}$ & $\begin{array}{c}18 \\
100.0\end{array}$ \\
\hline $\begin{array}{l}\text { Responding to } \\
\text { therapy }\end{array}$ & $\begin{array}{c}65 \\
52.9 \%\end{array}$ & $\begin{array}{c}58 \\
47.1 \%\end{array}$ & $\begin{array}{c}123 \\
100.0\end{array}$ \\
\hline Total & $\begin{array}{c}66 \\
46.8 \%\end{array}$ & $\begin{array}{c}75 \\
53.2 \%\end{array}$ & $\begin{array}{c}141 \\
100.0\end{array}$ \\
\hline
\end{tabular}

endometrial glands for the different therapy regimens were not related to relapse $(P=0.83)$.

Changes in $\boldsymbol{H}$-scores related to therapy response and relapse. In the LNG-IUS-treated group, all the women responded to therapy (48 out of 48). Of these, 3 had weak $H$-scores $(<0.5)(6 \%), 33$ had medium $H$-scores (0.6-1.0) (69\%), and 12 had high $H$-scores $(>1)$ (25\%) before the start of therapy. In the group treated with continuous oral progestin, only 2 of 44 women were nonresponders (2 out of 44). Of the responders, none had low $H$-scores, 35 had medium $H$-scores (80\%), and 7 had high $H$-scores (15.9\%), whereas the 2 non-responders had medium $H$-scores $(4.1 \%)$ before therapy.

In the group treated with cyclic oral progestin, 16 of the 49 women were non-responders (16 out of 49 ).

Among the responders, 4 (8.2\%) had low $H$-scores, 24 (49\%) had medium $H$-scores, and $5(10.2 \%)$ had high $H$-scores. In the nonresponding group, 15 (30.6\%) had medium $H$-scores, and $1(2 \%)$ had a low $H$-score. Changes in the $H$-score were significantly related to therapy response $(P<0.001)$; the results are shown in Table 2. Changes in the $H$-score were not related to relapse in the 24-month follow-up period after therapy was discontinued $(P=0.83)$. 
A

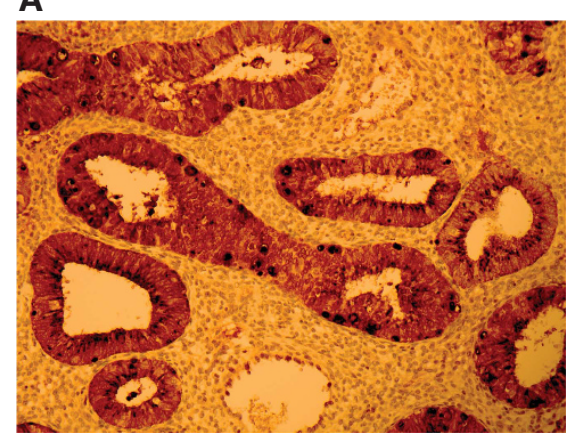

B

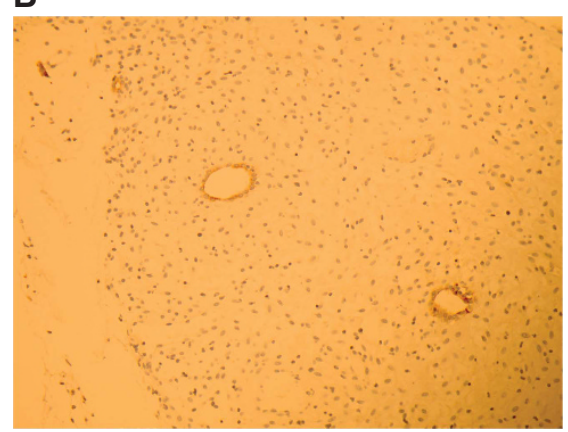

C

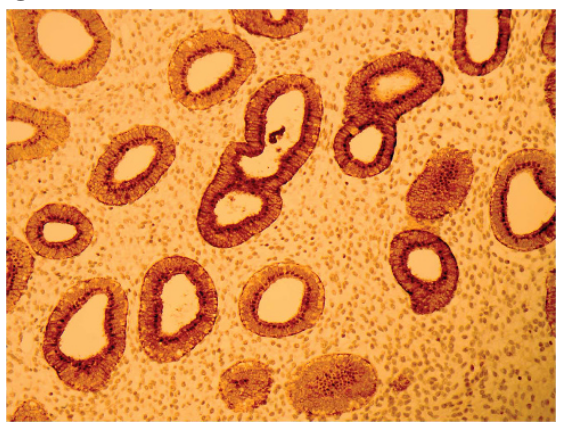

Figure 1. Expression of HE4 before and after progestin therapy. (A) Endometrial hyperplasia stained with HE4 (clone $12 \mathrm{~A} 2$ monoclonal IgG1 antibodies, Fujirebio Diagnostics, Inc.) before the start of therapy. The cytoplasm of the glandular cells is stained brown by HE4. Scattered intracellular HE4-stained bodies are observed randomly dispersed within the cells. (B) An endometrial specimen stained with HE4 (clone 12A2 monoclonal IgG1 antibody, Fujirebio Diagnostics, Inc.) after successful therapy by LNG-IUS. The endometrium is pseudo-decidualised, and the glands have become small and atrophic with a lack of HE4 staining. (C) Persistent endometrial hyperplasia stained with HE4 (clone 12A2 monoclonal lgG1 antibodies, Fujirebio Diagnostics, Inc.) after therapy failure. This woman had been given $10 \mathrm{mg}$ of MPA taken 10 days per cycle for 6 months.

Table 3. Change in the size of HE4-stained bodies (difference in pre- and post-treatment biopsies in aggregates of HE4stained material in the glandular cell cytoplasm) in women with and without therapy response after 6 months of

progestin therapy $(n=141)$ (10 mg of MPA) for 10 days per cycle, $10 \mathrm{mg}$ of MPA daily, or the levonorgestrel impregnated intrauterine system for 6 months) in a randomised controlled trial in women with endometrial hyperplasia

\begin{tabular}{|c|c|c|c|}
\hline $\begin{array}{l}\text { Therapy } \\
\text { response/ HE4- } \\
\text { stained bodies }\end{array}$ & $\begin{array}{c}\text { Size reduction or } \\
\text { absence of } \\
\text { HE4-stained } \\
\text { aggregates after } \\
\text { therapy } \\
N\end{array}$ & $\begin{array}{c}\text { Increase in size } \\
\text { of HE4-stained } \\
\text { aggregates after } \\
\text { therapy } \\
N\end{array}$ & Total \\
\hline $\begin{array}{l}\text { Not responding to } \\
\text { therapy }\end{array}$ & $\begin{array}{c}3 \\
16.7 \%\end{array}$ & $\begin{array}{c}15 \\
83.3 \%\end{array}$ & $\begin{array}{c}18 \\
100.00\end{array}$ \\
\hline $\begin{array}{l}\text { Responding to } \\
\text { therapy }\end{array}$ & $\begin{array}{c}20 \\
10.8 \% \\
\end{array}$ & $\begin{array}{c}110 \\
89.2 \% \\
\end{array}$ & $\begin{array}{c}123 \\
100.00\end{array}$ \\
\hline Total & $\begin{array}{c}31 \\
22.0 \%\end{array}$ & $\begin{array}{c}110 \\
78.0 \%\end{array}$ & $\begin{array}{c}141 \\
100.00\end{array}$ \\
\hline
\end{tabular}

Figure 1B shows HE4 expression after therapy failure in a woman treated with oral cyclic progestin. Figure 1C shows the lack of HE4 expression after treatment with LNG-IUS.

Changes in HE4-stained cellular bodies related to therapy response and relapse. Human epididymis-specific protein 4 bodies were observed as dark-brown granular aggregates varying in size between 2 and $15 \mu \mathrm{m}$ that were localised within the cell cytoplasm or in close proximity to the cell membrane. Intracellular localisation could be a regular apical row or random dispersal within the cells. These bodies were not observed by routine $\mathrm{H}+\mathrm{E}$ staining. Changes in the $H$-score of HE4-stained aggregates, which were intra- or intercellular bodies, were compared in pre- and post-treatment specimens. These changes were significantly correlated with therapy response $(P=0.038)$ (Table 3$)$ but not with the therapy group $(P=0.556)$. Changes in the HE4 bodies reflected the only HE4related parameter that could significantly predict relapse of endometrial hyperplasia $(P=0.014)$ (Tables 3 and 4$)$.

$\mathrm{H}$-scores related to WHO categorisation in pre-treatment biopsies. Table 5 shows that most of the included cases characterised as complex hyperplasia also had medium $H$-scores before the start of therapy.
Table 4. Difference in the size of HE4-stained bodies (difference in pre- and post-treatment biopsies in aggregates of HE4-stained material in the glandular cell cytoplasm) after 6 months of progestin therapy in women who never experienced relapse and those who later relapsed during 24 months of follow up $(n=123)$

\begin{tabular}{|c|c|c|c|}
\hline $\begin{array}{l}\text { Relapse of } \\
\text { hyperplasia/HE4- } \\
\text { stained bodies }\end{array}$ & $\begin{array}{c}\text { Size reduction or } \\
\text { absence of } \\
\text { HE4-stained } \\
\text { aggregates after } \\
\text { therapy } \\
N\end{array}$ & $\begin{array}{c}\text { Increase in size } \\
\text { of HE4-stained } \\
\text { aggregates after } \\
\text { therapy } \\
N\end{array}$ & Total \\
\hline No relapse & $\begin{array}{c}11 \\
15.1 \%\end{array}$ & $\begin{array}{c}62 \\
84.9 \%\end{array}$ & $\begin{array}{c}73 \\
100.00\end{array}$ \\
\hline Relapse & $\begin{array}{c}17 \\
34.0 \%\end{array}$ & $\begin{array}{c}33 \\
66.0 \%\end{array}$ & $\begin{array}{c}50 \\
100\end{array}$ \\
\hline Total & $\begin{array}{c}28 \\
22.8 \%\end{array}$ & $\begin{array}{c}95 \\
77.2 \%\end{array}$ & $\begin{array}{c}123 \\
100.00\end{array}$ \\
\hline
\end{tabular}

Table 5. Relationship between the $H$-score before therapy started and the WHO classification of the pre-treatment biopsies in a randomised controlled trial in women with endometrial hyperplasia $(n=141)$ randomised to different progestin therapy regimens (10 mg of MPA) for 10 days per cycle, $10 \mathrm{mg}$ of MPA daily, or the levonorgestrel impregnated intrauterine system for 6 months)

\begin{tabular}{|c|c|c|c|c|}
\hline & \multicolumn{3}{|c|}{ Classification of endometrial hyperplasia } & \\
\hline $\begin{array}{l}\mathrm{H} \text {-score/WHO } \\
\text { classification }^{\text {a }}\end{array}$ & $\begin{array}{c}\text { Simple } \\
\text { hyperplasia } \\
N\end{array}$ & $\begin{array}{c}\text { Complex } \\
\text { hyperplasia } \\
N\end{array}$ & $\begin{array}{c}\text { Atypical } \\
\text { hyperplasia } \\
N\end{array}$ & $\begin{array}{c}\text { Total } \\
N\end{array}$ \\
\hline $\mathrm{HE} 4 \leqslant 0.5$ & $\begin{array}{c}1 \\
5.0 \% \\
\end{array}$ & $\begin{array}{c}5 \\
4.8 \% \\
\end{array}$ & $\begin{array}{c}1 \\
6.3 \% \\
\end{array}$ & $\begin{array}{c}7 \\
5.0 \% \\
\end{array}$ \\
\hline HE4 0.5-1 & $\begin{array}{c}16 \\
80.0 \%\end{array}$ & $\begin{array}{c}81 \\
77.1 \%\end{array}$ & $\begin{array}{c}12 \\
75.0 \%\end{array}$ & $\begin{array}{c}109 \\
77.3 \%\end{array}$ \\
\hline $\mathrm{HE} 4 \geqslant 1$ & $\begin{array}{c}3 \\
15.0 \%\end{array}$ & $\begin{array}{c}19 \\
18.1 \%\end{array}$ & $\begin{array}{c}3 \\
18.7 \%\end{array}$ & $\begin{array}{c}25 \\
17.7 \%\end{array}$ \\
\hline $\begin{array}{l}\text { Total } \\
N\end{array}$ & $\begin{array}{c}20 \\
100.0\end{array}$ & $\begin{array}{c}105 \\
100.0\end{array}$ & $\begin{array}{c}16 \\
100.0\end{array}$ & $\begin{array}{c}141 \\
100.0\end{array}$ \\
\hline
\end{tabular}

Abbreviations: HE4=human epididymis-specific protein 4; $\mathrm{H}$-score=histological score; $\mathrm{MPA}=$ medroxyprogesterone acetate; $\mathrm{WHO}=$ World Health Organisation.

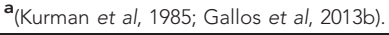


Changes in $\boldsymbol{H}$-scores in endometrial glands related to patient characteristics. When patient characteristics such as BMI $(<20$, $20-24,25-30$, and $>30$ ), menopausal status (pre-, peri-, and postmenopausal), or age ( $<45,45-48,49-51$, and $52+$ years) were compared with therapy regimen and therapy response, no significant relationship could be identified (data not shown) (Orbo et al, 2015).

\section{DISCUSSION}

To date, this is the first multicentre RCT to demonstrate that HE4 expression in biopsy material from endometrial hyperplasia can be monitored and regulated by progestin. The administered therapy regimens differed particularly in terms of the total dose of progestin yielded to the endometrial mucosa during the 6-month therapy period (Orbo et al, 2014). Consequently, significant differences in the HE4 score were observed between pre- and post-treatment biopsies for the three progestin therapy groups. A greater reduction in the HE4 score was observed with the LNG-IUS compared with oral therapy. The concentration of levonorgestrel, obtained by the LNGIUS in the uterine mucosa, has been shown to be more than 100 times higher than the concentration observed after oral treatment with the same type of progestin (Nilsson et al, 1982). All the women treated with the LNG-IUS in the present study obtained a complete therapy response after 6 months (Orbo et al, 2014). Thus, the reduction in the tissue expression of $\mathrm{HE} 4$ (reduced $\mathrm{H}$-score) appears to be associated with the given progestin dose.

However, the function of the HE4 protein family, known to serve as endogenous peptide protease inhibitors, remains obscure, and no specific molecular link between HE4 and progestin has ever been described (Jiang et al, 2013). In cell studies of ovarian cancer overexpression and knockout of HE4-related genes, HE4 has been shown to regulate malignant mechanisms such as cell adhesion, invasion, and proliferation (Jiang et al, 2013). Evidence exists that the tumour-promoting effects of HE4 are effectuated by the activation of the EGFR-MAPK molecular pathway, which further activates PI3K/Akt-mediated proliferation and other types of malignant behaviour (Lu et al, 2012; Liu et al, 2015). Several studies have demonstrated that the influence of progestin hormones on the PI3K signalling pathway can counteract the malignant effects (Minaguchi et al, 2007). Minaguchi et al (2007) demonstrated that medroxyprogesterone had an anti-tumour effect through the dephosphorylation of Akt. In another study, progesterone was shown to inhibit the oestradiol-stimulated Akt/ CyclinD1/pRB pathway, blocking endometrial proliferation (Chen et al, 2005). Thus, according to several in vitro studies, the possibility exists that progestin can counteract the malignant effect induced by HE4 in a dose-dependent manner, and this might be effectuated by the regulation of the PI3K signalling pathway. The exact mechanism for progestin resistance remains unknown. In the present study, 18 women showed resistance to progestin therapy with persistent hyperplasia after 6 months. Among these 18 women, 17 showed increased $H$-scores after therapy. All of these women had been treated with either oral cyclic (16 out of 18) or oral continuous progestin (2 out of 18). Thus, higher progestin doses might be required to reverse and suppress the unfavourable influence of high HE4 levels. Studies have been performed to investigate the molecular events related to progestin resistance and the reversion of progestin resistance in endometrial cancer. $\mathrm{Gu}$ et al (2011) have shown that low concentrations or the absence of progesterone receptors in endometrial cancer cells are associated with a poor response to progesterone therapy. Their results also indicated that activation of the PI3K/Akt pathway by progestin without PR mediation has an important role in progestin resistance to endometrial cancer ( $\mathrm{Gu}$ et al, 2011). In contrast, we have observed that progesterone receptors were completely absent after
3 months of LNG-IUS therapy in endometrial hyperplasia, even though the treatment effect was efficiently maintained over several years and all the included patients had responded to the therapy (Vereide et al, 2006; Orbo et al, 2008; Orbo et al, 2014). In the same study, both progesterone receptor $\mathrm{A}$ and progesterone receptor $\mathrm{B}$ were present in women with therapy failure after 3 months (Vereide et al, 2006). In endometrial cancer cell lines, we showed dose-dependent progestin effects using supra-physiological concentrations of progestin to ensure that the progesterone receptors were thoroughly saturated (Moe et al, 2009a,b). Taken together, these former studies indicate that non-genomic signalling pathways are activated by high progestin concentrations and that the effective suppression of HE4 may be dependent on high progestin concentrations.

Thus far, a link between the synthesis, cell transport, and serum levels of HE4 has not been clearly demonstrated. In recent studies, the tissue expression of HE4 localised in the cytoplasm in glands has been shown to increase in proportion to the increase in malignancy in endometrial proliferative conditions ( $\mathrm{Li}$ et al, 2015; Deng et al, 2015). The absence of HE4 occurred in benign endometrial lesions, but severe hyperplasia and low-grade cancer were characterised by stronger HE4 staining compared with simple and complex hyperplasia without atypia (Li et al, 2015; Deng et al, 2015). This is consistent with our results showing that the majority of the included women, who were treated conservatively, obtained a medium score of HE4 before therapy started. Human epididymis-specific protein 4 is a small secretory glycoprotein detected in the plasma, and HE4 levels have been described to increase proportionately with Figo stage and tumour grade (Li et al, 2015; Brennan et al, 2015). In addition, high levels of HE4 in the plasma have been shown to preoperatively identify high-risk patients with low-grade endometrial cancer with increased risks of lymph node metastases (Brennan et al, 2015). Our finding of HE4 bodies localised within the cytoplasm in endometrial epithelial cells has never been described. Even if our results indicate that changes in diameter of these bodies during therapy predicted relapse, the statistics was not powerful and these findings need to be further analysed in future studies.

The possibility exists that these aggregates of HE4 molecules might represent HE4 marker glycoproteins ready to be transported from intracellular compartments to the bloodstream, representing the missing link between tissue expression and measurable serum levels of HE4. Although immunohistochemistry has its limitations, the present study is based on a recently published RCT, which ensures the quality of the results.

In the current study, we found that changes in HE4 expression during therapy for endometrial hyperplasia were significantly related to the progestin therapy regimen and correlated to the therapy response but could not predict relapse. Our results suggest that changes in the expression of HE4 after various progestin therapy regimens can predict therapy response $v s$ therapy resistance. Thus, HE4 may be a useful tissue marker for women with medium- and low-risk endometrial hyperplasia who are intolerant to LNG-IUS and who can be successfully treated by oral progestin.

\section{ACKNOWLEDGEMENTS}

Fujirebio kindly provided the HE4 antibody but had no influence on the study project or the evaluation of the results. We also thank the Regional Research Board of Northern Norway (Helse Nord) for the grants.

\section{CONFLICT OF INTEREST}

The authors declare no conflict of interest. 


\section{REFERENCES}

Abu HH, Ghayaty E, El RM (2015) Levonorgestrel-releasing intrauterine system vs oral progestins for non-atypical endometrial hyperplasia: a systematic review and metaanalysis of randomized trials. Am J Obstet Gynecol 213(4): 469-478.

Bese T, Vural A, Ozturk M, Dagistanli F, Demirkiran F, Tuncdemir M, Arvas M, Sanioglu C, Kosebay D (2006) The effect of long-term use of progesterone therapy on proliferation and apoptosis in simple endometrial hyperplasia without atypia. Int J Gynecol Cancer 16: 809-813.

Bignotti E, Ragnoli M, Zanotti L, Calza S, Falchetti M, Lonardi S, Bergamelli S, Bandiera E, Tassi RA, Romani C, Todeschini P, Odicino FE, Facchetti F, Pecorelli S, Ravaggi A (2011) Diagnostic and prognostic impact of serum HE4 detection in endometrial carcinoma patients. Br J Cancer 104(9): 1418-1425.

Bouchard D, Morisset D, Bourbonnais Y, Tremblay GM (2006) Proteins with whey-acidic-protein motifs and cancer. Lancet Oncol 7: 167-174.

Brennan DJ, Hackethal A, Mann KP, Mutz-Dehbalaie I, Fiegl H, Marth C, Obermair A (2015) Serum HE4 detects recurrent endometrial cancer in patients undergoing routine clinical surveillance. BMC Cancer 15: 33-1028.

Buttini MJ, Jordan SJ, Webb PM (2009) The effect of the levonorgestrel releasing intrauterine system on endometrial hyperplasia: an Australian study and systematic review. Aust N Z J Obstet Gynaecol 49: 316-322.

Chen B, Pan H, Zhu L, Deng Y, Pollard JW (2005) Progesterone inhibits the estrogen-induced phosphoinositide 3-kinase- $>$ AKT- $>$ GSK-3beta$>$ cyclin D1-> pRB pathway to block uterine epithelial cell proliferation. Mol Endocrinol 19: 1978-1990.

Clark TJ, Neelakantan D, Gupta JK (2006) The management of endometrial hyperplasia: an evaluation of current practice. Eur J Obstet Gynecol Reprod Biol 125: 259-264.

Deng L, Gao Y, Li X, Cai M, Wang H, Zhuang H, Tan M, Liu S, Hao Y, Lin B (2015) Expression and clinical significance of annexin A2 and human epididymis protein 4 in endometrial carcinoma. J Exp Clin Cancer Res 34: 96-0208.

Drapkin R, von Horsten HH, Lin Y, Mok SC, Crum CP, Welch WR, Hecht JL (2005) Human epididymis protein 4 (HE4) is a secreted glycoprotein that is overexpressed by serous and endometrioid ovarian carcinomas. Cancer Res 65: 2162-2169.

Ferenczy A, Gelfand M (1989) The biologic significance of cytologic atypia in progestogen-treated endometrial hyperplasia. Am J Obstet Gynecol 160: 126-131.

Gallos ID, Krishan P, Shehmar M, Ganesan R, Gupta JK (2013a) LNG-IUS versus oral progestogen treatment for endometrial hyperplasia: a longterm comparative cohort study. Hum Reprod 28: 2966-2971.

Gallos ID, Krishan P, Shehmar M, Ganesan R, Gupta JK (2013b) Relapse of endometrial hyperplasia after conservative treatment: a cohort study with long-term follow-up. Hum Reprod 28: 1231-1236.

Gallos ID, Shehmar M, Thangaratinam S, Papapostolou TK, Coomarasamy A, Gupta JK (2010) Oral progestogens vs levonorgestrel-releasing intrauterine system for endometrial hyperplasia: a systematic review and metaanalysis. Am J Obstet Gynecol 203: 547.e1-10.

Gu C, Zhang Z, Yu Y, Liu Y, Zhao F, Yin L, Feng Y, Chen X (2011) Inhibiting the PI3K/Akt pathway reversed progestin resistance in endometrial cancer. Cancer Sci 102: 557-564.

Huang A, Pettigrew NM, Watson PH (1996) Immunohistochemical assay for oestrogen receptors in paraffin wax sections of breast carcinoma using a new monoclonal antibody. J Pathol 180: 223-227.

Jiang SW, Chen H, Dowdy S, Fu A, Attewell J, Kalogera E, Drapkin R, Podratz K, Broaddus R, Li J (2013) HE4 transcription- and splice variants-specific expression in endometrial cancer and correlation with patient survival. Int J Mol Sci 14: 22655-22677.

Jobo T, Kawaguchi M, Imai M, Kuramoto H (2001) Treatment for complex atypical hyperplasia of the endometrium. Eur J Gynaecol Oncol 22: 365-368.

Kalapotharakos G, Asciutto C, Henic E, Casslen B, Borgfeldt C (2012) High preoperative blood levels of HE4 predicts poor prognosis in patients with ovarian cancer. J Ovarian Res 5: 20-25.

Kurman RJ, Kaminski PF, Norris HJ (1985) The behavior of endometrial hyperplasia. A long-term study of "untreated" hyperplasia in 170 patients. Cancer 56: 403-412.

Li X, Gao Y, Tan M, Zhuang H, Gao J, Hu Z, Wang H, Zhu L, Liu J, Lin B (2015) Expression of HE4 in endometrial cancer and its clinical significance. Biomed Res Int 2015: 437468

Liu X, Zhao F, Hu L, Sun Y (2015) Value of detection of serum human epididymis secretory protein 4 and carbohydrate antigen 125 in diagnosis of early endometrial cancer of different pathological subtypes. Onco Targets Ther 8: 1239-1243.

Lu R, Sun X, Xiao R, Zhou L, Gao X, Guo L (2012) Human epididymis protein 4 (HE4) plays a key role in ovarian cancer cell adhesion and motility. Biochem Biophys Res Commun 419(2): 274-280.

Minaguchi T, Nakagawa S, Takazawa Y, Nei T, Horie K, Fujiwara T, Osuga Y, Yasugi T, Kugu K, Yano T, Yoshikawa H, Taketani Y (2007) Combined phospho-Akt and PTEN expressions associated with post-treatment hysterectomy after conservative progestin therapy in complex atypical hyperplasia and stage Ia, G1 adenocarcinoma of the endometrium. Cancer Lett 248: 112-122.

Moe BG, Vereide AB, Orbo A, Sager G (2009a) High concentrations of progesterone and mifepristone mutually reinforce cell cycle retardation and induction of apoptosis. Anticancer Res 29: 1053-1058.

Moe BT, Vereide AB, Orbo A, Jaeger R, Sager G (2009b) Levonorgestrel, medroxyprogesterone and progesterone cause a concentration-dependent reduction in endometrial cancer (Ishikawa) cell density, and high concentrations of progesterone and mifepristone act in synergy. Anticancer Res 29: 1047-1052.

Moore RG, Brown AK, Miller MC, Badgwell D, Lu Z, Allard WJ, Granai CO, Bast Jr. RC, Lu K (2008) Utility of a novel serum tumor biomarker HE4 in patients with endometrioid adenocarcinoma of the uterus. Gynecol Oncol 110(2): 196-201.

Moore RG, Miller MC, Disilvestro P, Landrum LM, Gajewski W, Ball JJ, Skates SJ (2011) Evaluation of the diagnostic accuracy of the risk of ovarian malignancy algorithm in women with a pelvic mass. Obstet Gynecol 118: 280-288.

Mutz-Dehbalaie I, Egle D, Fessler S, Hubalek M, Fiegl H, Marth C, Widschwendter A (2012) HE4 is an independent prognostic marker in endometrial cancer patients. Gynecol Oncol 126(2): 186-191.

Nilsson CG, Haukkamaa M, Vierola H, Luukkainen T (1982) Tissue concentrations of levonorgestrel in women using a levonorgestrelreleasing IUD. Clin Endocrinol (Oxf) 17: 529-536.

Okuda T, Sekizawa A, Purwosunu Y, Nagatsuka M, Morioka M, Hayashi M, Okai T (2010) Genetics of endometrial cancers. Obstet Gynecol Int 2010: 984013.

Orbo A, Arnes M, Hancke C, Vereide AB, Pettersen I, Larsen K (2008) Treatment results of endometrial hyperplasia after prospective $\mathrm{D}$-score classification. A follow-up study comparing effect of LNG-IUD and oral progestins versus observation only. Gynecol Oncol 111: 68-73.

Orbo A, Arnes M, Vereide AB, Straume B (2015) Relapse risk of endometrial hyperplasia after treatment with the levonorgestrel-impregnated intrauterine system or oral progestogens. BJOG 123: 1512-1519.

Orbo A, Vereide A, Arnes M, Pettersen I, Straume B (2014) Levonorgestrelimpregnated intrauterine device as treatment for endometrial hyperplasia: a national multicentre randomised trial. BJOG 121: 477-486.

Rodriguez AM, Schmeler KM, Kuo YF (2016) Lack of improvement in survival rates for women under 50 with endometrial cancer, 2000-2011. J Cancer Res Clin Oncol 142: 783-793.

Schulz KF, Altman DG, Moher D. (2010) CONSORT 2010 Statement: updated guidelines for reporting parallel group randomised trials. $B M C$ Med 8: 18.

Varma R, Soneja H, Bhatia K, Ganesan R, Rollason T, Clark TJ, Gupta JK (2008) The effectiveness of a levonorgestrel-releasing intrauterine system (LNG-IUS) in the treatment of endometrial hyperplasia-A long-term follow-up study. Eur J Obstet Gynecol Reprod Biol 139: 169-175.

Vereide AB, Kaino T, Sager G, Arnes M, Orbo A (2006) Effect of levonorgestrel IUD and oral medroxyprogesterone acetate on glandular and stromal progesterone receptors (PRA and PRB), and estrogen receptors (ER-alpha and ER-beta) in human endometrial hyperplasia. Gynecol Oncol 101: 214-223.

Wildemeersch D, Janssens D, Pylyser K, De WN, Verbeeck G, Dhont M, Tjalma W (2007) Management of patients with non-atypical and atypical endometrial hyperplasia with a levonorgestrel-releasing intrauterine system: long-term follow-up. Maturitas 57: 210-213.

This work is published under the standard license to publish agreement. After 12 months the work will become freely available and the license terms will switch to a Creative Commons AttributionNonCommercial-Share Alike 4.0 Unported License. 